\title{
NILAI-NILAI PENDIDIKAN KARAKTER; PENGUATAN BERBASIS KEGIATAN EKSTRAKURIKULER PRAMUKA DI PESANTREN
}

\author{
Fathor Rozi \& Uswatun Hasanah \\ Universitas Nurul Jadid \\ fathorrozi330@gmail.com, aanboan2403@gmail.com
}

\begin{abstract}
This study aims to understand how to carry out moral education through extracurricular activities in Islamic boarding schools. The values contained in scouts are very bigh, belping to install character values that are very suitable for basic students in forming moral values and fostering personality values in them. The methodology or approach used in this paper is through a library research method or approach.Collect data at the same time By viewing and / or exploring several quality books, journals and documents in print or electronic form and several sources of data or other information that are very important. Relaxation and research.Carrying out of extracurricular activities to increase the value of certain aspects What is found in the activities carried out including Take care of some things you can do Actually based on what students learn, or the environment needs. The process of cultivating personality values can be adjusted to the needs of students?The goal is that the values that can be instilled in students are correct internalization, especially in the selection or use of the scouting method.
\end{abstract}

Keywords : values of character education, scout extracurricular activities, Islamic boarding schools

\begin{abstract}
Abstrak : Penelitian ini bertujuan untuk memahami bagaimana melaksanakan pendidikan moral melalui kegiatan ekstrakurikuler di pesantren. Nilai yang terkandung dalam pramuka sangatlah tinggi membantu menanamkan nilai-nilai karakter yang sangat cocok untuk siswa dasar dalam membentuk nilai-nilai moral dan menumbuhkan nilai-nilai kepribadian didalamnya. Metodologi atau Pendekatan yang dipakai dalam tulisan ini melalui metode atau pendekatan kepustakaan (library research), Kumpulkan data pada saat bersamaan Dengan melihat dan / atau menjelajahi beberapa buku, jurnal dan Dokumen berkualitas dalam bentuk cetak atau elektronik dan Beberapa sumber data atau informasi lain yang sangat relevan Dan penelitian. Melaksanakan kegiatan ekstrakurikuler untuk meningkatkan nilai aspek tertentu Apa yang ditemukan dalam kegiatan yang dilakukan termasuk Jaga beberapa hal yang dapat Anda lakukan Sebenarnya berdasarkan apa yang dipelajari siswa Apa kebutuhan hidup mereka atau kebutuhan lingkungan Lingkungan sekitarnya. Proses penanaman nilai kepribadian dapat disesuaikan dengan kebutuhan peserta didik, Tujuannya agar nilai-nilai yang dapat ditanamkan pada siswa adalah Internalisasi yang benar, terutama dalam pemilihan atau penggunaan metode kepramukaan.
\end{abstract}

Kata Kunci : nilai-nilai pendidikan karakter, ekstrakurikuler pramuka, pesantren

Manazhim : Jurnal Manajemen dan Ilmu Pendidikan

Volume 3, Nomor 1, Februari 2021; 110-126

https:// ejournal.stitpn.ac.id/index.php/manazhim 


\section{PENDAHULUAN}

Salah satu yang menjadi institusi pondok pesantren yaitu orang-orang nonformal yang terpelajar mengatasi dan meminimalkan kurangnya semangat kerja bagi sebagian orang baru-bari di generasi muda. Lembaga ini menjadi lembaga pendidikan islam tertua di Indonesia. Dapat membina generasi kader ulama dan berperan dalam dunia Pendidikan masyarakat Indonesia. Selain itu, kegiatan pendidikan telah sukses menjadi titik tumpu semangat kewiraswastaan dan kemandirian ${ }^{1}$.

Kata "pesantren berasal dari kata "santri", kata "santri” diartikan sebagai murid dalam bahasa jawa. istilah "pondok" diambil bahasa Arab "dunduuq" yang artinya penginapan. Pesantren sebagai lembaga pendidikan sangat unik. Bukan karena keberadaan pesantren yang sudah ada sejak sangat lama, namun disebabkan adanya sebuah kultur, strategi, dan jaringan yang telah diterapkan dalam institusi agama tersebut ${ }^{2}$.

Sebuah sistem pendidikan didalam Pesantren berbentuk asrama sangat tradisional yang sudah menjadi tempat tinggal bagi seluruh santri juga tempat belajar ilmu tentang agama dibawah bimbingan guru atau yang kerap kita sebut dengan istilah kiai. Pengkajian ilmu yang termaktub dalam kurikulum yang telah diterapkan antara beberapa pesantren tentu berbeda. Dalam menetapkan kurikulum, pengasuh atau pengelola pondok pesantren mempertimbangkan situasi dan kondisi tempat, ragam usia, serta kebutuhan santri ${ }^{3}$.

Sistem pembelajaran di dalam Pesantren sangat menekankan pada pembinaan akhlaqul karimah. Hal ini sudah menjadi karakteristik bagi pesantren dibandingkan dengan lembaga formal lainnya. Pendidikan akhlak didalam pesantren menjadi hal yang utama. Seluruh aktivitas yang berlangsung di pesantren diimplementasikan pada pembuatan dan internalisasi nilai keislaman. Sebagian dari aktivitas yang dilaksanakan pada pembentukan nilai yakni kegiatan ekstrakulikuler yang mempunyai sasaran dari pencapaian sebagaimana visi serta misi pesantren tersebut. Ketika sistem budaya dan

${ }^{1}$ B. Marjani Alwi, 'Pondok Pesantren: Ciri Khas, Perkembangan, Dan Sistem Pendidikannya', Lentera Pendidikan: Jurnal Ilmu Tarbiyah Dan Keguruan, 16.2 (2016), 205-19 <https://doi.org/10.24252/lp.2013v16n2a8>.

${ }^{2}$ Imam Syafe'i, 'Lembaga Pendidikan Pembentukan Karakter', Al-Tadzkiyyah: Jurnal Pendidikan Islam, 8 (2015), 85-103.

${ }^{3}$ Ferdinan, 'Pondok Pesantren, Ciri Khas Perkembangannya', Jurnal Tarbawi, 53.9 (2018), 1689-99. 
sosial berubah, pendidikan hendak menjajaki perubahan atau pendidikan juga perlu diganti sebab pendidikan menjadi subsistem budaya atau subsistem sosial. Apabila perubahan sosial dapat dianggap linier, kemudian setelah perubahan diganti telah berpindah dari tradisional ke era modern ${ }^{4}$.

Kegiatan dari ekstrakurikuler dapat diartikan sebagai berkembangnya kegiatan ekstrakurikuler untuk siswa berkembang sesuai kebutuhan mereka, pengembangan potensi, minat serta bakat siswa melalui aktivitas khusus. Kegiatan ekstrakurikuler berkomitmen untuk meningkatkan aspek-aspek dalam kurikulum, serta hal-hal terpaut pelaksanaan praktis pembelajaran dengan metode tertentu oleh siswa dengan menyesuaikan dengan metode serta kebutuhan bagi kehidupan siswa ataupun lingkungan sekitarnya ${ }^{5}$.

Kegiatan ekstrakurikuler sudah lama diadakan di sekolah, dari sekolah paling dasar hingga universitas dengan pengaruh kecil untuk mengembangkan keterampilan siswa disebabkan oleh managemen kegiatan ekstrakurikuler disekolah belum maksimal, hanya mendorong mengembangkan minat dan bakat siswa ${ }^{6}$. Dengan demikian, kegiatan ekstrakurikuler pesantren diajarkan diluar kegiatan pembelajaran kitab mengaji al-quran. Kegiatan ektrakurikuler dipesantrren dianggap penting karena menjadi alat dalam pengembangan nilai peran mereka masuk sekolah biasa atau pembelajaran lainnya disekolah berasrama.

Dalam kegiatan ekstrakurikuler, semua santri bisa mempelajari serta mengaplikasikan nilai-nilai kreafitasan mereka dengan lebih kompleks jika dibandingkan belajar berada didalam kelas. Kegiatan ekstrakuler di pesantren menjadi usaha-usaha peningkatan keagamaan dan aktivitas, serta menjadi alternatif kreatif

\footnotetext{
${ }^{4}$ Amrizal, 'Eksistensi Tradisi Kajian Kitab Kuning Dalam Lingkup Perubahan Sosial (Studi Kasus Di Pesantren Darun Nahdhah, Darel Hikmah, Dan Babussalam)', Sosial Budaya, 13.1 (2017), 73-88.

5 Harpani Matnuh Noor Yanti, Rabiatul Adawiah, 'PELAKSANAAN KEGIATAN EKSTRAKURIKULER DALAM RANGKA PENGEMBANGAN NILAI-NILAI KARAKTER SISWA UNTUK MENJADI WARGA NEGARA YANG BAIK DI SMA KORPRI BANJARMASIN', Zhong Yao Cai = Zhongyaocai = Journal of Chinese Medicinal Materials, 36.10 (2013), 1573-76.

${ }^{6}$ Ria Yuni Lestari, 'Peran Kegiatan Ekstrakurikuler Dalam Mengembangkan Watak Kewarganegaraan Peserta Didik’, 1.2 (2016), 136-52.
} 
yang penerapannnya erat sekali dengan modul yang diberikan ${ }^{7}$. Sehingga, santri bisa memahami, menghayati serta mengamalkan dengan langsung kegiatan ekstarkulikuler keagamaan dalam upaya meningkatkan pendidikan islam.

Irwanto \& Jatiningsih(2013) mengatakan bahwa "pramuka merupakan kegiatan ekstrakurikuler yang ada pada jenjang pendidikan.” Artinya kegiatan pramuka merupakan kegiatan yang terapkan di sekolah universitas diluar jam belajar formal. Dalam kegiatan ekstrakurikuler kepramukaan, siswa dilatih serta dikembangkan nilai-nilai karakter bangsa ${ }^{8}$.

Supriadi berkata: "nilai-nilai karakter yang dikemukakan pada individu seseorang pembina pramuka adalah keyakinan diri, mentaati aturan sosial, menghormati keragaman, berfikir logis, berfikir kritis, inovatif, mandiri, berani, kerja keras, tekun/gigih, disiplin ketat, visioner, rendah hati, antutias, energik, fokus, terorganisir, konstruktif?."

Sementara itu menurut Ambiro Puji Asmaroini (2019), "mencari nilai itu dengan nilai-nilai positif yang sudah diajarkan dan ditanamkan pada semua anggota pramuka. Nilai-nilai merupakan nilai moral yang membumbui perilaku pramuka.” Kegiatan pramuka memberikan nilai-nilai kepribadian juga ciri khas bangsa orang baik. Dan mengatakan “ pramuka merupakan proses kegiatan pendidikan eksternal lingkungan sekolah juga keluarga membentuk kegiatan yang sehat, menarik, teratur, tepat sasaran dan praktis, itu adalah prinsip dasar kepramukaan. Gerakan pramuka pada akhirnya bertujuan untuk membentuk karakter, akhlak mulia dan budi pekerti luhur ${ }^{10}$."

\footnotetext{
${ }^{7}$ Nur Hidayat \& Azzah Zayyinah, 'PERAN EKSTRAKURIKULER DALAM MENINGKATKAN KARAKTER SANTRI PONDOK PESANTREN Nur Hidayat \& Azzah Zayyinah (Dosen PGMI FITK UIN Sunan Kalijaga Yogyakarta)', 1, 2014, 67-78.

8 A.C. \& Jatiningsih Irwanto, 'Peranan Kegiatan Ekstrakurikuler Pramuka Dalam Membentuk Kedisiplinan Siswa Di SMP Negeri 1 Sugio Kabupaten Lamongan', Jurnal Kajian Moral Dan Kewarganegaraan, 3.1 (2013), 549-63.

${ }^{9}$ Supriadi, 'Efektivitas Pengembangan Nilai-Nilai Karakter Bangsa Melalui Ekstrakurikuler Pramuka', Edutech, 13.3 (2014), 374 <https://doi.org/10.17509/edutech.v13i3.3091>.

10 Ambiro puji Asmaroini, 'Implementasi Nilai-Nilai Karakter Melalui Kegiatan Pramuka', 7 (2019), 28-39.
} 


\section{METODE PENELITIAN}

Metode penelitian ini menggunakan metode atau pendekatan library research, bisa juga studi pustaka atau literatur yang diartikan sebagai kegiatan yang berhubungan dengan metode pengumpulan data pustaka, pembacaan dan pencatatan, dan pengolahan bahan penelitian. Pada penelitian literatur setidaknya mempunyai empat kreteria utama yang harus diperhatikan, termasuk: pertama, penulis atau peneliti langsung mengolah teks atau data digital tanpa pengetahuan langsung dari tempat kejadian. Kedua, data pustakaan "siap pakai", artinya peneliti tidak terlibat langsung karena peneliti langsung mengerjakan sumber data yang berada di pustakaan. Ketiga, data pustakaan biasanya terdiri dari sumber sekunder, menunjukkan bahwa peneliti memperoleh informasi atau data bekas daripada datadata mentah dari bidang pertama. Keempat, kondisi data pustakaan tidak terbatas oleh ruang dan waktu ${ }^{11}$.

Berdasarkan hal diatas, pengumpulan data dalam penelitian yang dilaksanakan dengan cara mereview atau menjelajahi beberapa jurnal, buku dan pedoman (cetak dan eektronik) sumber data dan informasi lain yang diyakini relevan dengan riset atau studi.

\section{HASIL PENELITIAN DAN PEMBAHASAN}

\section{Nilai-nilai Karakter Utama dalam Kegiatan Ekstrakurikuler Pramuka}

\section{1) Nilai Religius}

Seiring dengan memudarnya rasa nasionalisme yang terjadi pada setiap generasi muda di indonesia disebabkan oleh arus globalisasi. Sifat religius perlu ditanamkan agar suatu negara bisa menunjukkan eksistensinya. Pendidikan karakter agama khususnya dikalangan para pemuda dalam pendidikan dasa dharma dan tri satya disertakan nilai-nilai agama. Tri satya nomor 1 artinya pramuka harus penuhi kewajiban dan perintah tuhan dan jauhi semua hal tabu. Dasa Dharma nomor 1 mengendung arti bahwa anak

11 Usman Yahya, 'Konsep Pendidikan Anak Usia Sekolah Dasar (6-12) Tahun Di Lingkungan Keluarga Menurut Pendidikan Islam’, Jurnal Islamika, 15.2 (2015), 227-44. 
pramuka wajib menjalankan perintah tuhan serta menjahui segala laranganNya, membaca do'a ketika mengawali dan mengakhiri pekerjaan sehari-hari, berbakti dan patuh kepada kedua orang tua, sayang kepada saudara, sesama, dan segala makhluk hidup ${ }^{12}$.

Pramuka menanamkan kegiatan keagamaan, kegiatan pramuka akan sangat mempengaruhi keyakinan beragama peserta jika kegiatan ekstrakurikuler penyidik dilaksanakan dan diikuti dengan baik, sehingga bisa meningkatkan keyakinan agama siswa ini baik $^{13}$. Dalam pelaksanaanya kegiatan pramuka banyak mengajarkan nilai-nilai religiusitas kepada siswa, kegiatan ini di adaptasikan, diselaraskan dengan tujuan, dibiasakan, diintegrasikan dalam kegiatan: 1. Berdo'a ketika memulai serta mengakhiri kegiatan kepramukaan atau apel. 2. Melakukan istirahat saat adzan dilantunkan dan sholat berjamaah. 3. Pengucapan juga memberikan pemahaman yang mendalam mengenai Tri Satya dan Dasa Dharma Pramuka ketika apel pembukaan kegiatan ekstrakurikuler. 4. Berkerja bakti membersihkan Mushola Sekolah

\section{2) Nilai Nasionalisme}

Nasionalisme berperan penting untuk negara, karena nasionalisme menjadi perwujudan kecintaannya masyarakat kepada tanah air dan nasionalisme berdasarkan nasionalisme pancasila membimbing manusia untuk memelihara keteguhan dan nilai-nilai kemanusiaan serta toleransi. Berbagai kegiatan bisa dimanfaatkan dalam membentuk sikap nasionalisme siswa penelitian tentang kegiatan ekstrakurikuler yang dapat mempengaruhi kegiatan itu dengan mengikuti kegiatan ekstrakurikuler, perkembangan intelektual siswa. Siswa membentuk sikap nasioanalis seperti sikap kepemimpinan siswa, keberanian, tanggung jawab dan kecintaan kepada

\footnotetext{
${ }^{12}$ Syamsul Bakhri and Alan Sigit Fibrianto, 'Hubungan Kegiatan Ekstrakurikuler Pramuka Dengan Tingkat Religiusitas Siswa Sma Negeri 1 Tangen (Perspektif Teori Sistem Sosial Talcott Parsons)', Jurnal Sosiologi Agama, 12.1 (2018), 67 <https://doi.org/10.14421/jsa.2018.121-04>.

13 Wahyuddin Naro Muhammad Taha, Arifuddin Siraj, Implementasi Gerakan Pramuka Dalam Pembentukan Karakter Peserta Didik Pondok Pesantren Madrasah Tsanawiyah Sultan Hasanuddin', Nanotechnology, 27.9 (2019), 3505-15.
} 
tanah air yang digali siswa melewati kegiatan pramuka ${ }^{14}$. Pramuka mengajari siswa bermacam hal berkaitan dengan pembentukan moralitas serta budi pekerti, bukan hanya pramuka namun juga mengajarkan caranya mengembangkan sikap baik, selalu taat kepada Tuhan, cinta kepada alam, kepada sesama manusia, mandiri dan hemat. Pramuka selalu melatuh keberanian, bukan hanya mengandalkan kebijaksanaan otak, tetapi juga mengajarkan bagaimana mengandalkan kecerdasan emosional yang mampu mempengaruhi sikap siswa.

Pendidikan ada mendidik siswa agar memiliki tingkat solidaritas tinggi dan semangat solidaritas yang kuat. Dan lewat kegiatan gerakan pramuka pembelajaran cinta tanah air, sikap menghargai budaya lain, menghormati agama lain, memakai bahasa Indonesia dengan baik dan benar. Gerakan pramuka juga mengajarkan kegiatan yg bertempat di alam terbuka seperti, saling membantu tanpa meliha ras, budaya, agama, hingga akhirnya dapat menjadikan sosok insan yang disiplin, mandiri dan membentuk karakter lebih baik.

Menggunakan inilah peran gerakan pramuka dalam menanam sikap nasionalisme. Kegiatan pramuka yaitu partisipasi rutin di kegiatan pramuka serta berpakaian dengan atribut lengkap, mendengarkan dan memperhatikan bahwa materi yang berhubungan dengan penanaman nasionalisme disediakan pelatih pramuka, berlatih, mempraktikan materi yang dijelaskan oleh pembina dan mengadakan bela negara dalam permainan-permainan pramuka, bernaynyi lagu-lagu nasional maupun lagu daerah, dan memakai bahasa Indonesia dengan baik dan benar. Hal tersebut diharapkan agar semua anggota pramuka siaga dan penggalang bisa membentuk karakter, akhlak baik, budi pekerti yang luhur, sikap disiplin, berani, saling menghargai, peduli lingkungan, cinta alam, memiliki kemandirian dan mental yang kuat. kegiatan pramuka dalam pembentukan diri dan kepribadian siswa melalui cara disiplin seperti menggunakan baju pramuka dengan atribut lengkap, dan percaya diri seperti menyayikan lagu nasional amaupun daerah sehingga meningkatkan

${ }^{14}$ Kabul Aris Surono, 'Penanaman Karakter Dan Rasa Nasionalisme Pada Kegiatan Ektrakurikuler Pramuka Di SMP N 4 Singorojo Kabupaten Kendal', 06.01 (2017). 
mental pada anak ${ }^{15}$. Semua hasil yang didapatkan siswa bisa digunakan untuk diolah masa depan. Berawal dari tujuan tersebut, terapkan pada aktivitas kegiatan pramuka menanamkan nasionalisme.

\section{3) Nilai Gotong Royong dan Kerja Sama}

karakter gotong royong terlihat ketika siswa bekerja sama dalam memecahkan setiap masalah berupa permainan beregu, sandi-sandi, petunjuk ketika penjelajahan, dan lain-lain. karakter gotong royong terlihat ketika siswa kerjasama, bermusyawarah, menghargai pemdapat, menolong sesama teman. Ini menjadi sebuah penerapan gotong royong dalam eskplorasi kegiatan ekstrakuerikuler. Siswa Membuat Pionering Tiang Bendera. Kegiatan tersebut dilakukan ketika penjelajahan dan berada disalah satu pos penjelajahan. Pembina pramuka juga selalu mengawasi jalannya penjelajahan termasuk ketika siswa membuat pionering. Pramuka menempati peran urgen dalam membentuk karakter siswa, khususnya dalam kerjasama atau kerjasama hal kebaikan. Kegiatan pramuka akan mengajari siswa untuk selalu bekerjasama atau kegiatan kerjasama dilaksanakan dengan itikad baik. Dalam kegiatan pramuka, siswa akan asah untuk selalu berkerjasama dan gotong royong atau kegiatandilakukan secara kerjasama dalam kebaikan. Karena pramuka memang menjunjung tinggi prinsip kekeluargaan ${ }^{16}$.

Melalui kegiatan pramuka, siswa mendapatkan kegiatan bersama seperti, gotong royong dan membuat tandu. Akan membimbing siswa kerjasama, saling membantu dan kekompakan dalam rangka pembagian tugas dipercahkan dengan cepat. Menanamkan nilai penting kerjasama, karena kerjasama dan sifat manusia menjadi keberadaan sosial yang saling membutuhkan dan membutuhkan orang lain. Oleh sebab itu, siswa wajib dilatih untuk bekerjasama sejak kecil. Sebagai makhluk sosial yang saling membutuhkan, pasti sangat butuh bantuan dan campur tangan dari orang

15 Uswatun Taubah, Mufatihatut., chasanah, 'PERANAN GERAKAN PRAMUKA DALAM MENANAMKAN SIKAP NASIONALISME DI MADRASAH IBDTIDAIYAH (Studi Kasus Di MIN Kudus Tahun Pelajaran 2017/2018)', ELEMENTARY: Islamic Teacher Journal, 6.2 (2018), 33754.

${ }^{16}$ Sri Arfiah and Bambang Sumardjoko, 'PENGUATAN KARAKTER TANGGUNG JAWAB DAN KEMANDIRIAN PADA MAHASISWA PPKN MELALUI PERKULIAHAN KEPRAMUKAAN', 27.2 (2017), 76-92. 
lain. Item aktivitas pramuka penting untuk membentuk karakter siswa yang ramah kerjasama. Dalam mendalami kegiatan ekstrakurikuler, siswa selalu belajar bekerjasama dalam berbagai hal ${ }^{17}$.

Contoh kerjasama dalam kegiatan pramuka: peran anggota tim memberikan masukan untuk bisa menemukan jawaban dari masalah tersebut. Peran itu memberikan keuntungan kelompok, termasuk siswa bisa mencapai keinginan bersama, menambah pengetahuan, memecahkan masalah yang belum pernah ditemui, menjadikan setiap siswa lebih sigap ketika memecahkan masalah yang dihadapi sekelompok orang, mengembangkan keberanian setiap orang, mengekspresikan pendapat dan tingkatkan kesadaran dalam kelompok agar setiap siswa selalu menghadapi masalah bersama. Dengan demikian, kegiatan berkelompok sesama siswa membuka kesempatan berkembang dalam nuansa persaudaraan untuk menumbuhkan keinginan untuk lebih baik. Melewati kegiatan gotong royong, siswa akan kebih banyak memahami segala macam hal yang siswa tidak mengerti. Siswa bisa bertukar pikiran. Dengan bekerjasama, siswa akan merasakan apa adanya rasa lebih gampang dan cepat untuk melalukan keseatu, tetapi harus tetap dalam latar belakang yang baik. Karena melaksanakan sesuatu bersama membuat orang merasa rileks. Kegiatan ekstrakurikuler pramuka berehubungan erat penyelenggaraan pendidikan karakter, terutama untuk menanamkan sikap gotong royong seerta kerjasama.

\section{4) Nilai Integritas}

Salah satu dari makna yang ada dalam Dasa Dharma Pramuka yaitu "Rajin, Terampil dan Gembira" memiliki keterkaitan yang tersirat dengan keilmuan. Dengan demikian 'terampil' disini dikatakan sebagai anjuran bagi setiap siswa agar menguasai banyak hal. Jika ingin menjadi orang terampil, siswa sudah pasti harus mempelajari serta menyelami ilmu tersebut, dan mengamalkannya dengan baik sehingga kita bisa disebut 'terampil'. Dengan kata lain, supaya menjadi terampil, kita terlebih dahulu harus menjadi orang berilmu. Dan tentunya, untuk memperoleh ilmu kita harus banyak

${ }_{17}$ Singgih Adhi Prasetyo and Husnul Hadi, 'Penanaman Nilai-Nilai Pendidikan Karakter Siswa Melalui Kegiatan Ekstrakulikuler Pramuka’, 2019, 114-21. 
mempelajari materi dan mengambil pelajaran dari pengalaman kehidupan. Siswa tidak hanya berkomunikasi dengan antar sesama anggota melainkan juga berkomunikasi dengan pembina pramuka, begitu juga sebaliknya. Pembina pramuka tidak segan mengajak siswa untuk memberikan contoh cara berkomunikasi yang baik dan benar ${ }^{18}$.

Ketika siswa berkomunikasi juga tidak pernah memakai kata-kata yang kotor. karakter integritas terlihat ketika siswa berinteraksi dengan sesama maupun dengan pembina, bertanggung jawab menjadi petugas apel, melakukan wawancara ketika penjelajahan, dan lain-lain.

\section{5) Karakter Kemandirian}

Kepramukaan sangat membantu untuk membentuk dan peningkatan karakter siswa, terutama kemandirian, kegiatan ekstrakurikuler membentuk prauka mandiri seperti, baris-berbaris, membuat tenda, bertahan hidup dalam camping dan permainan yang sering kali digunakan di berbagai tempat kegiatan pramuka. Pengalaman siswa diperoleh dalam mengeksplorasi kegiatan ekstrakurikuler sangat berguna saat mengajar pramuka di sekolah. Nilai karakter kemandirian yang terhubung dengan kegiatan pramuka juga sangat berguna dan bagus dalam formasi kerakter dari semua siswa yang lulus ${ }^{19}$.

Penanaman nilai-nilai karakter mandiri kepada siswa ketika berkemah adalah keberanian menghadapi tantangan dan mengambil suatu keputusan saat dihadapkan dalam permasalahan atau tugas, selalu membangun rasa percaya diri pada diri sendiri serta mempunyai kemampuan dalam melalukan tugas dan mengetahui kemampuann sendiri. Selain nilai peran independen, kegiatan berkemah merupakan kegiatan yang bisa dijadikan patokan bagi siswa dalam mengetahui tingkat aplikasi siswa yang tergabung dalam anggota pramuka yang menerapkan kemandirian dalam kehidupan sehari-hari.

${ }^{18}$ Ibnu Hanif, 'Peranan Pembina Pramuka Dalam Mengembangkan Karakter Kepemimpinan Siswa Di SMP Negeri 3 Depok Sleman', 3.42 (2014), 95-104.

${ }^{19}$ Devyta Restu Prihanawati, 'PENGARUH KEAKTIFAN MENGIKUTI EKSTRAKURIKULER PRAMUKA TERHADAP KEMANDIRIAN SISWA KELAS V SD NEGERI CIBUK LOR SEYEGAN SLEMAN', 1.1 (2018), 35-44. 


\section{Strategi Pendidikan Karakter dalam Kegiatan Ekstrakurikuler Pramuka}

1) Pembiasaan

Berdasarkan pembiasaan, seseorang dapat terbiasa melakukan beberapa kegiatan yang bermanfaat bagi kehidupannya. Pembahasan tentang pembiasaan selalu menjadi suatu objek yang penting untuk diketahui. Inti dari kebiasaan adalah pengalaman. Kebiasaan juga merupakan usaha sebenarnya dari pelatih daam membangun peran. Coba ingat-ingat bahwa manusia mempunyai sifat lupa dan lemah. Keyakinan bantin bersifat dinamis yang artinya ketidakstabilan selalu dipengaruhi oleh pengaruh luar seseorang. Sama halnya di kegiatan ekstrakurikuer pramuka. Kegiatan keagamaan yang dilakukan menerapkan agar peserta didik tetap membiasakan diri dengan beberapa kegiatan seperti, mengembangkan kebiasaan dengan memberi tahu siswa untuk tepat waktu, saling menyapa, melakukan sholat berjamaah, dan lain-lain. Keteladanan yaitu memberikan contoh perilaku kepada siswa secara langsung. Tetapkan tugas, seperti kapan harus melaksanakan kegiatan kemah dan mendapatkan tugas individu dan kelompok. Berikan pidato mejelaskan pentingnya nilai-nilai yang terkandung dalam pancasila, dan lain-lain. Hukuman atau sanksi bagi anggota pramuka yang melanggar aturan peringatan langsung oleh supervisor ${ }^{20}$.

\section{2) Keteladanan}

Gaya interior aspek pendidikan metode yang berpengaruh dan terbukti paling berhasil, membentuk suasana moral dan sosial siswa. Ingat, pendidik perspektif siswa akan meniru sikap dan peilaku pendidik. Dalam hal ini keteladanan harus dilakukan oleh guru dan seluruh karyawan dan pejabat sekolah. Menurut penjelasan yang patut dicontoh terbagi menjadi dua, yaitu: keteladanan tidak disengaja, dan keteladanan sengaja. Paradigma yang tidak disengaja adalah teladan sains atau pembelajaran, kepemimpinan dan ketulusan. Pramuka bisa jadi tempat paling efktif untuk membangun kesadaran dan kepedulian lingkungan. Contoh yang diberikan oleh Kwartir Cabang Pramuka memberikan konstribusi yang besar dalam mendidik 
karakter anggota pramula. Keteladanan pramuka lebih banyak mengusulkan aspek perilaku untuk membentuk tindakan konkret. Setiap anggota pramuka berintegrasi dengan lingkungan melalui aktivitasnya. Kesadaran dan perhatian terhadap lingkungan secara alami tidak akan tumbuh dengan cara ini, tapi itu harus membentuk terus-menerus, melalui aktivitas nyata dan kedekatan dengan kehiduan sehari-hari ${ }^{21}$.

\section{3) Tanggung jawab}

Nilai tanggung jawab juga menjadi nilai penting untuk diinternalisasikan karena tanggung jawab berkaitan erat dengan pelaksanaan tugas dan kewajiban sehingga orang yang bertanggung jawab akan melaksanakan semua tugas serta kewajibannya dengan baik dan berani menanggung resiko sebagai konsekuensi dari tanggung jawabnya. ${ }^{22}$.

Sifat bertanggung jawab atas diri sendiri dalam kegaiatan pramuka seperti menjaga kesehatan dan jaga kebersihan pribadi. Bisa dilakukan istirahat yang cukup, makan dengan teratur, ikut senam. Peran aktif kegiatan ekstrakurikuler untuk membangun rasa tanggung jawab, bangun pagi bersama saat berkemah, membersihkan tubuh, mandi, basuh kaki dan tangan, berpakaian rapi. Mewajibkan siswa untuk menjaga kesehatan dan kebersihan diri agar tidak jatuh sakit di dalam ruangan kegiatan tersebut, agar siswa dapat mengamati semua kegiatan dan perilaku untuk menyelesaikan tugas dengan benar.

Selain itu, siswa tidak boleh lupa belajar sebagai bentuk tanggung jawab siswa. Belajar adalah tugas utama seorang siswa, sehingga sesibuk apapun para siswa dalam melakukan aktivitasnya harus tetap bertanggung jawab untuk tidak melupakan tugasnya untuk belajar. Penyusunan program kegiatan Pramuka yang sudah dilakukan oleh pembina pramuka dapat memperhatikan kondisi dan keadaan siswa sehingga tidak mengganggu kegiatan pembelajaran di sekolah. Menjaga kesadaran siswa tentang kesehatan

21 Sa'adah Erliani, 'Peran Gerakan Pramuka Untuk Membentuk Karakter Kepedulian Sosial Dan Kemandirian (Studi Kasus Di SDIT Ukhwah Dan MIS An-Nuriyyah 2 Banjarmasin) INFORMASI ARTIKEL', 2.1 (2016), 36-46.

22 Slamet Sumarto Penny Trianawati Maman Rachman, 'PENANAMAN NILAI TANGGUNGJAWAB MELALUI EKSTRAKURIKULER KEPRAMUKAAN DI SMP NEGERI 13 SEMARANG', 2.2 (2013). 
fisik dan mental juga rasa tanggung jawab kepada siswa bisa dikatan satu bentuk tanggung jawab kepada siswa ${ }^{23}$.

\section{4) Disiplin}

Nilai disiplin juga diinternalisasikan oleh guru karena nilai disiplin merupakan kunci sukses seseorang jika ingin berhasil, artinya kedisiplinan faktor utama yang akan menentukan keberhasilan seseorang karena kediplinan terkait dengan management waktu dan managemen diri. Sikap disiplin itu sangat dibutuhkan oleh siswa, karena sikap disiplin memiliki beberapa manfaat, antara lain: tidak menganggap remeh suatu pekerjaan, menumbuhkan sikap menghargai waktu, mempunyai sikap tanggung jawab yang besar, dan menumbuhkan kepatuhan pada peraturan. Menanamkan serta mengembangkan disiplin siswa dalam kegiatan pramuka bukan melalui pengajaran, bukan melalui indoktinasi/paksaan, tetapi dengan kesadaran diri melalui aktivitas menyenangka, menantang yang mengandung pendidikan dan dilakukan secara berkesinambungan, sehingga pada diri peserta didik tumbuh kesadaran bahwa mematuhi peraturan merupakan kita menuju sukses $^{24}$.Dalam mengeksplorasi kegiatan ekstrakurikuler, siswa mendapatkan bahan ajar ciri kedisiplinan juga diintegrasikan dala bentuk pendidikan investigasi mampu memprakterkkan ilmu yang diperoleh dalam ehidupan sehari-hari.

\section{5) Saling menghargai}

Nilai saling menghormati juga bisa dilalui dengan interaksi, karena dibutukan sikap timbal balik dalam berinteraksi apresiasi, agar interaksi dapat dilakukan secara harmonis dalam suasana yang menguntungkan. Saling menghargai ini sangat diperlukan dalam pergaulan masyarakat yang majemuk, terdiri dari berbagai suku, beragam agama, beragam budaya dan beragam latar belakang pendidikan. Mengembangkan tujuan nilai saling menghormati

\footnotetext{
23 Sri Woro dan Marzuki, 'PERAN KEGIATAN EKSTRAKURIKULER PRAMUKA DALAM PEMBENTUKAN KARAKTER TANGGUNG JAWAB PESERTA DIDIK DI SMP NEGERI 2 WINDUSARI MAGELANG', 2016, 59-73.

${ }_{24}$ Nur Qoyimatul Uyun Al Azizi, 'Kegiatan Ekstrakurikuler Kepramukaan Terhadap Pendidikan Karakter Kedisiplinan', Jurnal Pendidikan Luar Sekolah, 12.2 (2020), 1 <https://doi.org/10.32832/jpls.v12i2.2793>.
} 
diantara siswa untul membentuk siswa yang sensitif dan peduli, menghargai perbedaan $^{25}$.

Contoh dalam kegiatan lomba hari pramuka. Kegiata tersebut merupakan implementasi dan pengembangan dari kegiatan kepramukaan, didasari kode kehormatan pramuka. Menang atau kalah bukan suatu masalah bagi para pramuka sejati. Sportivitas dan saling menghargai sesama peserta, serta keinginan lebih untuk memperbaiki diri itu yang diharapkan. Sehingga dapat memunculkan bibit-bibit baru yang semangat kepramukaan.

\section{KESIMPULAN}

Berdasarkan hasil penelitian dan pembahasan diatas dapat kita menyumpulkan bahwa kegiatan ekstrakurikuler itu sangat penting bagi semua aspek perkembangan kurikulum tertentu dan sedang berlangsung, termasuk yang berterkaitan dengan penerapan praktis ilmu yang telah dipelajari oleh siswa menyesuaikan dengan kebutuan sehari-hari juga lingkungan sekitarnya. Kegiatan ekstrakurikuler didalam peran pesantren sangatlah penting karena telah menjadi alat dalam pengembangan nilai-nilai karakter. Teori-teori yang sudah didapat di sekolah biasa atau kegiatan pembelajaran di sekolah berasrama. Kegiatan ekstrakurikuler di pesantren menjadi usaha-usaha peningkatan kegiatan keagamaan diluar jam sekolah kegiatan ini menjadi salah satu opsi inovatif yang diterapkan sangat dekat dengan materi yg dipelajari di kelas sehingga siswa bisa dipahami, jalani dan praktikkan langsung degiatan ektrakurikuler agama untuk meningkatkan pendidikan islam. Nilainilai tersebut adalah nilai moral dan akan mempengaruhi perilaku anggota pramuka. Kegiatan pramuka memberikan nilai kepribadian dan karakter bangsa yang baik. Nilai peran juga dapat dianggap sebagai cara berfikiir untuk bekerjasama khusus untuk setiap orang dan kehidupan msyarakat secara keseluruhan keluarga, komunitas, negara dana negara bagian. Bahkan dapat menafsirkan nilai karakter sebagai nilai dasar dalam pembentukan kepribadian

${ }^{25}$ Idawati Novri Gazali, Romi Cendra, Oki Candra, Leni Aprianti, 'Aksiologiya : Jurnal Pengabdian Kepada Masyarakat Penanaman Nilai-Nilai Karakter Peserta Didik Melalui Ekstrakurikuler Pramuka', 3.2 (2019), 201-10. 
Proses penanaman nilai kepribadian bisa mesesuaikan dengan kebutuhan siswa, tujuannya agar nilai-nilai yang dapat ditanamkan pada siswa adalah terinternalisasi dengan baik terutama dalam pemilihan maupun penggunaan metode kepramukaan. Penanaman nilai pendidikan karakter menggunakan cara praktek langsung sesuai dengan tujuan gerakan pramuka, yaitu dalam semangat trisatya dan dasa dharma Kegiatan pramuka berdampak positif bagi siswa. Selain itu siswa bisa memperoleh pengalaman melalui kegiatan pramuka, juga siswa bisa meningkatkan keterampilan dan kemampuan dalam pembentukan nilai karakter yang baik bagi siswa. Karena diluar kelas, pramuka berisi nilai pendidikan karakter bangsa Indonesia. Kegiatan pramuka mengajari siswa tentang peran. Nilai karakter religius nampak pada saat pembelajaran akan dimulai dan ketika mengakhiri kegiatan dengan berdoa dan beribadah kepada Tuhan Yang Maha Esa. Kebiasaan menanamkan nilai karakter dalam kegiatan pramuka juga diterapkan di kegiatan belajar.

\section{DAFTAR PUSTAKA}

Alwi, B. Marjani, 'Pondok Pesantren: Ciri Khas, Perkembangan, Dan Sistem Pendidikannya', Lentera Pendidikan: Jurnal Ilmu Tarbiyah Dan Keguruan, 16.2 (2016), 205-19<https://doi.org/10.24252/lp.2013v16n2a8>

Amrizal, 'Eksistensi Tradisi Kajian Kitab Kuning Dalam Lingkup Perubahan Sosial (Studi Kasus Di Pesantren Darun Nahdhah, Darel Hikmah, Dan Babussalam)', Sosial Budaya, 13.1 (2017), 73-88

Arfiah, Sri, and Bambang Sumardjoko, 'PENGUATAN KARAKTER TANGGUNG JAWAB DAN KEMANDIRIAN PADA MAHASISWA PPKN MELALUI PERKULIAHAN KEPRAMUKAAN', 27.2 (2017), 76-92

Asmaroini, Ambiro puji, 'Implementasi Nilai-Nilai Karakter Melalui Kegiatan Pramuka', 7 (2019), 28-39

Al Azizi, Nur Qoyimatul Uyun, 'Kegiatan Ekstrakurikuler Kepramukaan Terhadap Pendidikan Karakter Kedisiplinan', Jurnal Pendidikan Luar Sekolah, 12.2 (2020), 1 <https://doi.org/10.32832/jpls.v12i2.2793>

Bakhri, Syamsul, and Alan Sigit Fibrianto, 'Hubungan Kegiatan Ekstrakurikuler Pramuka Dengan Tingkat Religiusitas Siswa Sma Negeri 1 Tangen (Perspektif Teori Sistem Sosial Talcott Parsons)', Jurnal Sosiologi Agama, 12.1 (2018), 67 <https://doi.org/10.14421/jsa.2018.121-04>

Erliani, Sa'adah, 'Peran Gerakan Pramuka Untuk Membentuk Karakter Kepedulian Sosial Dan Kemandirian (Studi Kasus Di SDIT Ukhwah Dan MIS An-Nuriyyah 2 Banjarmasin) INFORMASI ARTIKEL', 2.1 (2016), 36-46 
Ferdinan, 'Pondok Pesantren, Ciri Khas Perkembangannya', Jurnal Tarbawi, 53.9 (2018), 1689-99

Hanif, Ibnu, 'Peranan Pembina Pramuka Dalam Mengembangkan Karakter Kepemimpinan Siswa Di SMP Negeri 3 Depok Sleman', 3.42 (2014), 95-104

Irwanto, A.C. \& Jatiningsih, 'Peranan Kegiatan Ekstrakurikuler Pramuka Dalam Membentuk Kedisiplinan Siswa Di SMP Negeri 1 Sugio Kabupaten Lamongan', Jurnal Kajian Moral Dan Kewarganegaraan, 3.1 (2013), 549-63

Lestari, Ria Yuni, 'Peran Kegiatan Ekstrakurikuler Dalam Mengembangkan Watak Kewarganegaraan Peserta Didik', 1.2 (2016), 136-52

Marzuki, Sri Woro dan, 'PERAN KEGIATAN EKSTRAKURIKULER PRAMUKA DALAM PEMBENTUKAN KARAKTER TANGGUNG JAWAB PESERTA DIDIK DI SMP NEGERI 2 WINDUSARI MAGELANG', 2016, 59-73

Muhaemin, 'PENGARUH PENDIDIKAN PRAMUKA TERHADAP PEMBENTUKAN KARAKTER RELIGIUS PADA ANGGOTA PRAMUKA', 4.1 (2019), 111-20

Muhammad Taha, Arifuddin Siraj, Wahyuddin Naro, 'Implementasi Gerakan Pramuka Dalam Pembentukan Karakter Peserta Didik Pondok Pesantren Madrasah Tsanawiyah Sultan Hasanuddin', Nanotechnology, 27.9 (2019), 3505-15

Noor Yanti, Rabiatul Adawiah, Harpani Matnuh, 'PELAKSANAAN KEGIATAN EKSTRAKURIKULER DALAM RANGKA PENGEMBANGAN NILAINILAI KARAKTER SISWA UNTUK MENJADI WARGA NEGARA YANG BAIK DI SMA KORPRI BANJARMASIN', Zhong Yao Cai = Zhongyaocai = Journal of Chinese Medicinal Materials, 36.10 (2013), 1573-76

Novri Gazali, Romi Cendra, Oki Candra, Leni Aprianti, Idawati, 'Aksiologiya : Jurnal Pengabdian Kepada Masyarakat Penanaman Nilai-Nilai Karakter Peserta Didik Melalui Ekstrakurikuler Pramuka', 3.2 (2019), 201-10

Penny Trianawati Maman Rachman, Slamet Sumarto, 'PENANAMAN NILAI TANGGUNGJAWAB MELALUI EKSTRAKURIKULER KEPRAMUKAAN DI SMP NEGERI 13 SEMARANG', 2.2 (2013)

Prasetyo, Singgih Adhi, and Husnul Hadi, 'Penanaman Nilai-Nilai Pendidikan Karakter Siswa Melalui Kegiatan Ekstrakulikuler Pramuka', 2019, 114-21

Prihanawati, Devyta Restu, 'PENGARUH KEAKTIFAN MENGIKUTI EKSTRAKURIKULER PRAMUKA TERHADAP KEMANDIRIAN SISWA KELAS V SD NEGERI CIBUK LOR SEYEGAN SLEMAN', 1.1 (2018), 3544

Supriadi, 'Efektivitas Pengembangan Nilai-Nilai Karakter Bangsa Melalui $\begin{array}{llll}\text { Ekstrakurikuler Pramuka, } \quad \text { Edutech, } & 13.3 \quad \text { (2014), } & 374\end{array}$ $<$ https://doi.org/10.17509/edutech.v13i3.3091>

Surono, Kabul Aris, 'Penanaman Karakter Dan Rasa Nasionalisme Pada Kegiatan Ektrakurikuler Pramuka Di SMP N 4 Singorojo Kabupaten Kendal', 06.01 (2017) 
Syafe'i, Imam, 'Lembaga Pendidikan Pembentukan Karakter', Al-Tad₹kiyyah: Jurnal Pendidikan Islam, 8 (2015), 85-103

Taubah, Mufatihatut., chasanah, Uswatun, 'PERANAN GERAKAN PRAMUKA DALAM MENANAMKAN SIKAP NASIONALISME DI MADRASAH IBDTIDAIYAH (Studi Kasus Di MIN Kudus Tahun Pelajaran 2017/2018)', ELEMENTARY: Islamic Teacher Journal, 6.2 (2018), 337-54

Yahya, Usman, 'Konsep Pendidikan Anak Usia Sekolah Dasar (6-12) Tahun Di Lingkungan Keluarga Menurut Pendidikan Islam', Jurnal Islamika, 15.2 (2015), 227-44

Zayyinah, Nur Hidayat \& Azzah, 'PERAN EKSTRAKURIKULER DALAM MENINGKATKAN KARAKTER SANTRI PONDOK PESANTREN Nur Hidayat \& Azzah Zayyinah (Dosen PGMI FITK UIN Sunan Kalijaga Yogyakarta)', 1, 2014, 67-78 